\title{
American Medical Association Journal of Ethics
}

\author{
April 2016, Volume 18, Number 4: 422-429
}

POLICY FORUM

Would People with Intellectual and Developmental Disabilities Benefit from Being Designated "Underserved"?

Lyubov Slashcheva, Rick Rader, MD, and Stephen B. Sulkes, MD

Despite social movements in favor of equality in health care, fiscal and political realities often lead to inequality: that is, those with the resources and skills to navigate the health care system and to access care remain well, while the "have-nots" retain an increased disease burden [1]. As Cynthia Jones proposes, such health disparities "are morally problematic because they exemplify and aid in perpetuating a centuries-old system of injustices" [2]. One response to this moral problem is prioritarianism, which, Leslie Scheunemann et al. explain, "attempts to help those who are considered worst off by giving them priority in situations in which all cannot receive a particular resource.... The goal is to give all individuals equal opportunity to live a normal life span" [3]. In the United States, the federal government indicates regions or groups in need of priority access to certain health care resources by designating them medically underserved areas or populations (MUAs or MUPs, respectively). Medically underserved areas are designated on the basis of a physical or numerical shortage of primary care clinicians for a given geographic region. Although certain regions may have sufficient clinicians per square mile, people in various demographic groups (e.g., based on income level or other factors) may still not be able to access necessary services; recognizing such demographic groups as medically underserved populations could help acknowledge this problem.

\section{The Example of American Indians as Medically Underserved}

Although designating residents of rural areas as medically underserved has expanded opportunities to profoundly and positively affect the health of these populations [4], the

prioritarian response to the health disparities facing American Indians has not succeeded in alleviating those disparities.

Prioritarian programs. In 1956, the Indian Health Service (IHS) was established to provide for the health care of members of Indian tribes [5]. The Indian Health Care Improvement Act, passed in 1976 [6] and permanently reauthorized in 2010 [5],

contained a vast array of provisions designed to increase the quantity and quality of Indian health services...[including] consolidation and authorization of funding for existing IHS programs, funding authorization for facilities construction, and authorization for health and medical 
services for urban Indians... IHCIA authorized Medicare and Medicaid reimbursement for services performed in Indian health facilities [7].

In 1980, the federal government's Health Professional Shortage Area (HPSA) designation was introduced [8]; members of Indian tribes and health care facilities that receive funds allocated by the 1976 act are designated HPSAs [9].

Persistent disparities. These efforts, however, have not eliminated disparities or the persistent disease burden faced by American Indians. Compared to the overall population, the life expectancy for American Indians is 4.2 years less than that for the population overall [10], and they "are more likely than the overall population to report being in fair or poor health, being overweight or obese, having diabetes and cardiovascular disease, and experiencing frequent mental distress" [11].

When they are compared to Caucasians, the disparities are even more striking:

American Indians and Alaska Natives have an infant death rate 60 percent higher than the rate for Caucasians. Al/ANs are twice as likely to have diabetes as Caucasians.... Al/ANs also have disproportionately high death rates from unintentional injuries and suicide. In 2012, the tuberculosis rate for Al/NAs was 6.3, as compared to 0.8 for the White population [12].

The literature mentions two main causes for the persistence of these disparities: chronic lack of funding for Indian health programs [13-15] and "issues that prevent them from receiving quality medical care...cultural barriers, geographic isolation, inadequate sewage disposal, and low income" [12]. Efforts to address these factors have been introduced over time, but have not yet succeeded in overcoming them. All this suggests that challenges that individuals and communities face in accessing care and maintaining health are multifactorial and may not be adequately addressed by the groups' mere designation as underserved.

\section{The Argument for Designating Persons with Disabilities as a Medically Underserved Population}

People with disabilities certainly face health disparities. In a recent review boasting the provocative title "Persons with Disabilities as an Unrecognized Health Disparity," Gloria Krahn et al. [16] note that "adults with disabilities are 4 times more likely to report their health to be [only] fair or poor than people with no disabilities" [17]. Seeking reasons for this finding, the authors point to lack of access to care. They report that "adults with disabilities are 2.5 times more likely to report skipping or delaying health care because of cost" [18] and that, "although they have higher rates of chronic diseases than the general population, adults with disabilities are significantly less likely to receive 
preventive care" [18]. Others have detailed that "children with SHCHNs [special health care needs] and their families represent an important underserved population....

Substantial disparities are present in access, satisfaction, and family impact" [19].

Beyond literature references, the co-authors of this article can attest from careers of caring for patients with intellectual and developmental disabilities (IDD), in which they interface with thousands of patients and their families each year, that families' reports overwhelmingly echo the documented findings: that (across the life span) patients with disabilities experience a patchwork form of uncoordinated health care that leaves them without adequate access to essential health care services. Additionally, a 2002 report from the US surgeon general noted that, "compared with other populations, adults, adolescents, and children with MR [mental retardation (sic)] experience poorer health and more difficulty in finding, getting to, and paying for appropriate health care" [20].

There are many examples of "cultivated care" — the term one of us (RR) has used elsewhere to describe health care delivered in a comprehensive, coordinated, caring, culturally competent, and continuous fashion-for people with IDD. This intentional practice model may be instrumental in reducing health care disparities affecting persons with IDD when coupled with innovations such as the medical home, appropriate case management, targeted physician and dentist training, preventive measures, expanded knowledge about secondary conditions, and medical advocacy. But alone it is still not enough to address the disparities documented in the surgeon general's report; one potential (and probably critical) impediment to addressing these disparities is the nondesignation of this population as medically underserved. Underserved population designation could bring about several benefits [21] for the IDD population: scholarship or loan repayment incentives for clinicians to serve this population, the expansion of physician and dentist training in the care of persons with IDD, funding for expanded prevention and screening of people with IDD, community health center grants to provide care specifically to the IDD population, prioritization in research of issues affecting people with IDD, and the inclusion of people with IDD in clinical trials - particularly in later-stage therapeutic research.

In response to documented disparities, the American Academy of Developmental Medicine and Dentistry (AADMD) appointed a Task Force on Health Disparities, which affirms that persons can be at risk of being medically underserved regardless of their zip code, ethnic roots, or primary language, and, where appropriate, this should be recognized (unpublished data). Based on our data, it seems clear that the phrase "where appropriate" applies to persons with IDD. The AADMD leadership used the definition employed by the Health Resources and Services Administration (HRSA) to ascertain the appropriateness of recognizing persons with IDD as an MUP: according to HRSA, a population can be considered medically underserved if its Index of Medical Underservice (IMU) score is less than 62.0. This score accounts for multiple features of a population, 
including poverty, mortality rate, age, and clinician density — meaning how many clinicians in a given specialty, such as mental health, primary care, or dentistry, exist in a given area or patient population [22]. The resultant IMU score for persons with IDD is 54.1 which is well below the determination threshold of 62.0.

\section{Would Designation Make the Right Difference?}

Even if designation did occur, merely improving marginalized persons' access to the health care system cannot change the experience of health care for a person, family, community, or population. Designating people with IDD as an MUP will not necessarily promote or ensure high-quality "cultivated care" for them.

There are numerous impediments to high-quality care for people with IDD. Given that people of color and people with disabilities both face social and cultural marginalization, it is reasonable to infer that the disparities faced by people of color may be similar to those confronted by people with IDD. The Institute of Medicine's [23] focus groups on addressing racial disparities in health care cited impediments to high-quality care, including the negative effects of some health care professionals' attitudes (e.g., stereotyping, lack of respect for patients, improper diagnosis and treatment), communication barriers, and financial barriers.

A few of these hurdles to high-quality care for people with IDD include the following:

1. Health care professionals are not adequately exposed to this population during training [24].

2. Medical professionals lack knowledge of logistics (motivation, competence, liability avoidance, and confidence) involved in providing care to persons with IDD [25].

3. Treatment of patients with IDD is poorly reimbursed, which discourages some from treating the complex needs of persons with IDD [25].

4. Informed consent for patients with IDD may be complicated by guardianship (i.e., the legal designation of another person as the patient's decision maker), which requires extra effort and increases clinician concern about effectively communicating with patients, managing complex conditions, and the risk of litigation and malpractice [25].

5. The medical model's focus on cure is still prevalent, which may be irrelevant or harmful to the experience of health and well-being that persons with IDD experience.

6. Clinicians are often inadequately equipped to collaborate with colleagues in other specialties or care management organizations to coordinate the care of their patients with IDD, which hinders their ability to attend to all their clients' needs and contributes to a sense of futility and self-insufficiency (all of which might hinder satisfaction in caring for persons with IDD) [25]. 
7. At times, the expectations for a "normal" life that families have for their members with IDD may be unrealistic, introducing tension into the patientclinician relationship that discourages the development of creative, individualized long-term treatment plans and calls into question whether the patient's selfdetermination is guiding the planning [25].

8. Ongoing invisibility, marginalization, and devaluation of people with IDD can negatively influence clinical encounters by convincing both patients and clinicians that it is acceptable for persons with IDD to receive second-tier health care [26]. These complex obstacles to optimal care for persons with IDD all need to be addressed. Although important, an MUP designation cannot fully respond to the barriers described because they are more complex than a simple lack of access to care.

\section{Conclusion}

Despite these remainders, however, the official recognition of people with IDD as an MUP would be a welcome complement to ongoing efforts to address obstacles to care. Prominent organizations, including the American Medical Association [27] and the American Dental Association [28], have passed resolutions affirming the need for this crucial step and now join the efforts of the AADMD in advocating for ensuring that those whose society has not offered sufficient supports can experience well-being as fully as possible.

\section{References}

1. Kington RS, Smith JP. Socioeconomic status and racial and ethnic differences in functional status associated with chronic diseases. Am J Public Health. 1997;87(5):805-810.

2. Jones CM. The moral problem of health disparities. Am J Public Health. 2010;100(suppl 1):S47.

3. Scheunemann LP, White DB. The ethics and reality of rationing in medicine. Chest. 2011;140(6):1628.

4. Mayer Davis EJ, D'Antonio AM, Smith SM, et al. Pounds off with empowerment (POWER): a clinical trial of weight management strategies for black and white adults with diabetes who live in medically underserved rural communities. Am J Public Health. 2004;94(10):1736-1742.

5. Indian Health Service. Basis for health services. https://www.ihs.gov/newsroom/factsheets/basisforhealthservices/. Accessed March 3, 2016.

6. Indian Health Care Improvement Act of 1976, Pub L No. 94-437, 90 Stat 1400. https://www.ssa.gov/OP_Home/comp2/F094-437.html. Accessed March 3, 2016.

7. Shelton BL. Issue brief: legal and historical roots of health care for American Indians and Alaska Natives in the United States. Kaiser Family Foundation; 2004: 10-11. https://kaiserfamilyfoundation.files.wordpress.com/2013/01/legal-and- 
historical-roots-of-health-care-for-american-indians-and-alaska-natives-inthe-united-states.pdf. Accessed March 3, 2016.

8. Center for Rural Health. Health professional shortage areas (HPSAs) and medically underserved areas (MUAs). https://ruralhealth.und.edu/pdf/hpsa.pdf. Accessed March 3, 2016.

9. US Department of Health and Human Services Health Resources and Services Administration. American Indian/Alaska Native: shortage designation. http://www.hrsa.gov/publichealth/community/indianhealth/shortage.html. Accessed March 3, 2016.

10. Indian Health Service. Fact sheet: disparities. https://www.ihs.gov/newsroom/factsheets/disparities/. Accessed March 3, 2016.

11. Artiga S, Arguello R, and Duckett P. Health coverage and care for American Indians and Alaska Natives. Kaiser Family Foundation; 2013. http://kff.org/disparities-policy/issue-brief/health-coverage-and-care-foramerican-indians-and-alaska-natives/. Accessed March 3, 2016.

12. US Department of Health and Human Services Office of Minority Health. Profile: American Indian/Alaska Native. Updated February 3, 2016. http://minorityhealth.hhs.gov/omh/browse.aspx?|vl=3\&lvlid=62. Accessed March 3, 2016.

13. Jones DS. The persistence of American Indian health disparities. Am J Public Health. 2006;96(12):2122-2134.

14. Robert Wood Johnson Foundation. Significant health care needs of American Indians and Alaska Natives living in urban areas go unmet. 2007. http://www.rwjf.org/en/library/articles-and-news/2007/11/significant-healthcare-needs-of-american-indians-and-alaska-nat.html. Accessed March 3, 2016.

15. Sarche M, Spicer P. Poverty and health disparities for American Indian and Alaska Native children: current knowledge and future prospects. Ann N Y Acad Sci. 2008; 1136:126-136.

16. Krahn G, Walter DK, Correa-De-Araujo R. Persons with disabilities as an unrecognized health disparity. Am J Public Health. 2015;105(suppl 2):S198-S206.

17. Krahn, Walter, Correa-De-Araujo, S198.

18. Krahn, Walter, Correa-De-Araujo, S201.

19. van Dyck PC, Kogna MD, McPherson MG, Weissman GR, Newacheck PW. Prevalence and characteristics of children with special health care needs. Arch Pediatr Adolesc Med. 2004;158(9):884.

20. Office of the Surgeon General; National Institute of Child Health and Human Development; Centers for Disease Control and Prevention. Closing the Gap: A National Blueprint to Improve the Health of Persons with Mental Retardation. Washington, DC: US Department of Health and Human Services; 2002. https://www.nichd.nih.gov/publications/pubs/closingthegap/Pages/sub4.aspx\# problems. Accessed March 4, 2016. 
21. See, for example, Massachusetts Department of Public Health. The federal shortage designation process: health professional shortage areas (HPSA), medically underserved areas (MUA), medically underserved populations (MUP): a guide prepared for citizens, communities, health care organizations, and providers in Massachusetts. Updated July 2013. http://www.mass.gov/eohhs/docs/dph/com-health/primary-care/shortagedesignations-benefits.doc. Accessed March 4, 2016.

22. US Department of Health and Human Services Health Resources and Services Administration. Medically underserved areas/populations: guidelines for MUA and MUP designation. http://www.hrsa.gov/shortage/mua/. Accessed March 4, 2016.

23. Smedley BD, Stith AY, Nelson AR, eds; Institute of Medicine Committee on Understanding and Eliminating Racial and Ethnic Disparities in Health Care. Unequal Treatment: Confronting Racial and Ethnic Disparities in Health Care. Washington, DC: National Academies Press; 2003.

24. Holder M, Waldman HB, Wood H. Preparing health professionals to provide care to individuals with disabilities. Int J Oral Sci. 2009;1(2):66-71.

25. Harder + Company Community Research Group. A blind spot in the system: health care for people with developmental disabilities: findings from stakeholder interviews. September 2008.

http://odpc.ucsf.edu/sites/odpc.ucsf.edu/files/pdf_docs/A\%20Blind\%20Spot\%20 in\%20the\%20System.pdf. Accessed March 3, 2016.

26. Douthitt Stief H, Clark M. A survey of patients, families and providers about care of patients with intellectual disabilities. American Academy of Developmental Medicine and Dentistry; 2013. https://aadmd.org/articles/survey-patientsfamilies-and-providers-about-care-patients-intellectual-disabilities. Accessed March 4, 2016.

27. American Medical Association. H-90.969 Early intervention for individuals with developmental delay. https://www.amaassn.org/ssl3/ecomm/PolicyFinderForm.pl?site=www.amaassn.org\&uri=/resources/html/PolicyFinder/policyfiles/HnE/H-90.969.HTM. Accessed March 4, 2016.

28. Rader R. American Dental Association passes MUP resolution [news release]. Prospect, KY: American Academy of Developmental Medicine and Dentistry; October 14, 2014. http://aadmd.org/articles/american-dental-associationpasses-mup-resolution. Accessed March 4, 2016.

Lyubov Slashcheva is a fourth-year dental student at the Virginia Commonwealth University School of Dentistry in Richmond. Upon graduating with her DDS in 2016, she will enroll in the University of lowa College of Dentistry dental public health master of science program and the Geriatric and Special Needs Dentistry certificate program. As a National Health Service Corps Dental Scholar, Lyubov aims to establish a career in 
improving the oral health and well-being of vulnerable populations, including older adults and persons with intellectual or developmental disabilities.

Rick Rader, MD, is director of the Morton J. Kent Habilitation Center within the Orange Grove Center and an adjunct professor in human development at the University of Tennessee-Chattanooga in Chattanooga, Tennessee. He serves on the Board of the American Academy of Developmental Medicine and Dentistry and has focused his career on healthcare innovations in intellectual/neurodevelopmental disabilities, aging, and dementia.

Stephen B. Sulkes, MD, is co-director of the Strong Center for Developmental Disabilities and of the University Center of Excellence in Developmental Disabilities (UCEDD) program within the Division of Neurodevelopmental and Behavioral Pediatrics at the University of Rochester Medical Center in Rochester, New York. A board certified developmental-behavioral pediatrician, Dr. Sulkes serves on the Board of the American Academy of Developmental Medicine and Dentistry.

\section{Related in the AMA Journal of Ethics}

Closing the Gap: Finding and Encouraging Physicians Who Will Care for the Underserved, May 2009

Medicaid Reform: Implications for the Health Care Safety Net, July 2005

Federal and State Initiatives to Recruit Physicians to Rural Areas, May 2011

A Case for Special Programs to Expand the Ranks of Rural Physicians, May 2011

The Indian Health Service and Traditional Indian Medicine, October 2009

The Success of Telehealth Care in the Indian Health Service, December 2014

The viewpoints expressed in this article are those of the author(s) and do not necessarily reflect the views and policies of the AMA. 
Copyright 2016 American Medical Association. All rights reserved.

ISSN 2376-6980 